\title{
GENERIFICANDO A PESQUISA SOBRE ENDIVIDAMENTO IMOBILIÁRIO: PRIMEIROS DESAFIOS
}

\author{
Flávia Elaine da Silva Martins* \\ Ana Clara Guedes** \\ *Universidade Federal Fluminense, Programa de Pós-graduação em Geografia, Niterói, RJ, Brasil \\ **Universidade Federal Fluminense, Departamento de Geografia, Niterói, RJ, Brasil
}

\begin{abstract}
Resumo
Esta pesquisa objetiva refletir sobre a presença do endividamento no cotidiano urbano. Com enfoque no endividamento imobiliário, revela um caminho que envolve pesquisas iniciadas com relação à metrópole de São Paulo e que tiveram continuidade com a Região Metropolitana do Rio de Janeiro. Um de seus principais propósitos é enfrentar a carência de dados e o silenciamento do debate acerca da presença do endividamento imobiliário e da consequente expulsão silenciada. Como desafio, busca corporificar seus estudos, com centralidade no entrecruzamento dos dados de gênero e classe social e com recorte analítico nos editais de leilões de imóveis da Caixa Econômica Federal, refletindo e revelando uma Geografia do Endividamento. Além disso, dá os passos iniciais para um diálogo crítico sobre o peso da dívida e da casa para a mulher em um contexto de precarização, assimetria de remuneração e significação hierárquica entre trabalho produtivo e reprodutivo.

Palavras-chave

Endividamento; Metrópole; Rio de Janeiro; Imobiliário; Gênero.
\end{abstract}




\title{
ARTICLES
}

DOSSIER TERRITORY, GENDER AND INTERSECTIONALITIES

\section{GENDERING THE HOUSING INDEBTEDNESS RESEARCH: INITIAL CHALLENGES}

\author{
Flávia Elaine da Silva Martins* \\ Ana Clara Guedes** \\ *Universidade Federal Fluminense, Programa de Pós-graduação em Geografia, Niterói, RJ, Brazil \\ **Universidade Federal Fluminense, Departamento de Geografia, Niterói, RJ, Brazil
}

\begin{abstract}
This research intends to reflect on the presence of indebtedness in urban daily life. With a focus on housing indebtedness, it reveals a path of research followed, from research for the metropolis of São Paulo to Rio de Janeiro. It has as one of its main purposes to face the lack of data and the silencing of debate about the presence of real estate indebtedness and the consequent silenced expulsion. As a challenge, it aims to embody its studies, with a central focus on the intersection of gender and social class data. It has an analytical cut in the Real Estate Auction Notice of Caixa Econômica Federal, reflecting and revealing a Geography of Debt. Besides that, it takes the initial steps to critically discuss the weight of debt and the home for women in a context of precariousness, asymmetry of remuneration and hierarchical significance between productive and reproductive work.
\end{abstract}

Keywords

Indebtedness; Metropolis; Rio de Janeiro; Housing; Gender. 


\section{GENERIFICANDO A PESQUISA SOBRE ENDIVIDAMENTO IMOBILIÁRIO: PRIMEIROS DESAFIOS}

Flávia Elaine da Silva Martins

Ana Clara Guedes

Introdução

A ideia central deste artigo se constrói no enfrentamento de alguns desafios. O primeiro deles está em revelar o contexto de endividamento imobiliário urbano que cresceu em nossas cidades e metrópoles na última década, mas é tema pouco abordado. O segundo consiste em revelar tempos e espaços desse endividamento, ou seja, uma geografia do endividamento imobiliário. Por fim, deparamos durante a realização deste dossiê com algo que já fazia parte de nossa pesquisa e diz respeito à corporificação dos sujeitos endividados.

Nosso contexto de pesquisa está centrado no endividamento imobiliário como aspecto relevante da compreensão da urbanização metropolitana na atualidade. Iniciamos nossas indagações a fim de identificar os endividados. Consideramos insuficiente uma resposta que apontasse para um sujeito universalizado. Para esse caminho de pesquisa, investigamos atualmente a Geografia do Endividamento imobiliário na Região Metropolitana do Rio de Janeiro e a ela relacionamos dados e percursos teóricos anteriores, em que o objeto de estudo era a metrópole de São Paulo.

O endividamento é apontado como um recurso de reprodução social crítica nas metrópoles, cuja expressão geográfica será interpretada com base no desvelamento dos leilões de imóveis, situados em seus contextos geográficos desiguais. $\mathrm{O}$ endividamento está apoiado na assignação do trabalho futuro, em uma sociedade de ocupações precarizadas e rendas reduzidas.

Em nossos últimos exercícios, passamos a refletir sobre as possíveis assimetrias de gênero presentes na vulnerabilização social inscrita no endividamento. 
Essas assimetrias poderão ser intensificadas quando interseccionadas às questões raciais e de classe. Segundo Tavares (2017, p. 4), "o lugar, o tempo, a classe social, a geração e a raça/etnia também operam de forma coexistensiva”, instigando-nos a promover o entrecruzamento das características sociais de análise.

Para este dossiê, procedemos ao exercício de produção e análise de dados capazes de nos ajudar a correlacionar o endividamento e os rendimentos desiguais entre gêneros, apontando para níveis de exploração e espoliação com presença mais acentuada no modo de vida das mulheres trabalhadoras e endividadas nas metrópoles. Destaca-se, desta forma, a necessidade de refletir sobre a possível vulnerabilização1 da mulher no contexto do endividamento. Vale ressaltar que a "mulher" será compreendida aqui não de forma essencializada, e sim como "construção social do significado do gênero feminino” (TAVARES, 2017, p. 4).

Nossa reflexão aponta ainda para a espacialidade da mulher no cotidiano metropolitano. Considerando nosso enfoque no endividamento imobiliário, o debate traz à luz também o "peso da casa" diante do endividamento, pois, além da reiteração do papel desempenhado pela habitação como espaço de contingenciamento e superexploração da mulher, há arranjos familiares e ritmos de intensificação do trabalho na manutenção do pagamento de uma dívida de longo prazo. Objetivamos, por fim, enfrentar camadas de silenciamento.

Estudar o endividamento familiar, com ênfase na dívida imobiliária, trouxe e ainda traz um conjunto de desafios que se refletem até mesmo na coleta e na sistematização de dados. Para tanto, pretendemos apresentar como o estudo se estruturou e como serão dadas respostas aos desafios recentes. O contexto de surgimento deste estudo, suas bases de método e seus desafios metodológicos iniciais compõem a primeira parte do artigo. Um segundo momento busca discutir esse endividamento geograficamente, relacionando desde as escalas corpóreas até a constituição de dinâmicas territoriais e urbanas. Por fim, um terceiro movimento nos pareceu obrigatório, e diz respeito à identificação de dados que revelem as dificuldades e as vulnerabilidades econômicas pelas quais as mulheres passam em nossa sociedade, construindo a hipótese de que tais vulnerabilidades encontram reforço no endividamento. Assim, este estudo se iniciou com o propósito de articular o endividamento imobiliário ao modo de vida cotidiano nas metrópoles, localizando a dívida como um elemento coercitivo e impositor de ritmos de exploração e espoliação do/da trabalhador/a.

1. Vulnerabilidade e vulnerabilização são termos que merecem cuidado. Dependendo da forma como são utilizados, escondem sujeitos reais da ação e podem constituir certa externalidade na análise. Serão aqui empregados em caráter provisório, considerando a vulnerabilidade diante da expulsão da casa por endividamento. 
Em nosso caminhar, construímos pontes entre dados que revelam o momento crítico das dívidas, que é quando ocorre a expulsão da casa, e os dados gerais de alguns municípios, relacionando desemprego, renda e expulsão. Entretanto, nosso foco recai sobretudo na procura por respostas às seguintes indagações: de que forma o endividamento imobiliário pode atingir as mulheres e como construir essa informação?

São perguntas iniciais, sabemos. Não responderemos com dados às hipóteses implícitas, que estão no entorno do que definimos aqui, de forma reduzida, como vulnerabilização econômica. Miramos compreender futuramente as dinâmicas de opressão e violência que abarcam a "divisão" de papéis entre homens e mulheres nas formas produtivas e reprodutivas do trabalho, respectivamente, confinando a mulher aos cuidados familiares e domésticos, construindo sua dependência da renda masculina para o pagamento das prestações ou a sobrecarregando em sua jornada para fazer frente às diversas funções assumidas, financeiras e afetivas.

\section{A geografia do endividamento: desafios e percursos}

Esta pesquisa se iniciou com enfoque na metrópole de São Paulo. Estávamos em 2011 e a mudança de paisagem dos bairros em São Paulo e nos municípios da região metropolitana se caracterizava pela formação de condomínios verticais em antigas áreas de ocupação residencial horizontal. Muitos estudos foram feitos sobre essa realidade, mas pouco se falava de uma dinâmica subjacente, o crescimento dos financiamentos imobiliários e do consequente endividamento que passava a fazer parte do cotidiano dos novos moradores.

Alguns desafios estavam postos, e o primeiro deles era verificar como esse endividamento estava se realizando. Em um momento diferente do que vivemos hoje no Brasil, com índices de emprego e renda mais elevados, uma análise conjuntural não sustentava a preocupação com a inadimplência. Contudo, esta pesquisa se iniciou pautada em uma reflexão sobre a reprodução ampliada do capital como um movimento crítico, fazendo com que nossa hipótese fosse tanto de ampliação do endividamento imobiliário como recurso de financiamento produtivo e de circulação financeirizada, especialmente com a presença da securitização nas negociações, como de expressão da espoliação urbana, registrada na intensificação de jornadas de trabalho e na ampliação das expulsões.

Partimos para investigar a expressão dessas expulsões e encontramos respaldo nos leilões de imóveis. Ainda incipientes, as estratégias de facilitação de retomada dos imóveis já se faziam presentes nos leilões, em particular na figura da alienação fiduciária, que separava posse e propriedade e agilizava a retomada dos bens imóveis. O estudo dos leilões em São Paulo foi cartografado utilizando como 
base municípios e regiões metropolitanas, além de ter sido comparado com o mapeamento de lançamentos imobiliários.

De forma geral, o mapeamento dos leilões revelou maior incidência de casos no município de São Paulo do que em municípios das regiões metropolitanas de São Paulo e da Baixada Santista. Essa condição foi verificada nos mapeamentos de diferentes empresas leiloeiras e diferentes agências financiadoras, o que nos levou a inferir que se tratava de uma recorrência na situação geográfica dos imóveis leiloados. Em todos os casos, o município de São Paulo apresentou o maior número de imóveis leiloados na comparação com outros municípios das regiões metropolitanas e com o estado de São Paulo. No mapa referente ao número de lançamento de unidades habitacionais novas, em condomínios verticais ou horizontais, o inverso foi constatado. Os lançamentos se situavam destacadamente nos municípios da região metropolitana, e não no município de São Paulo em si.

Essas informações se complementavam e nos levaram a ensaiar algumas considerações: os incorporadores procuravam os municípios mais afastados para seus lançamentos, tendo em vista o preço mais baixo da terra. Os leilões, por sua vez, aconteciam em proporção maior nos imóveis do município de São Paulo. Os financiamentos imobiliários tiveram impacto no aumento do preço dos imóveis, tornando-os inviáveis para muitos compradores. De forma associada, esses dois dados mostravam que os imóveis leiloados eram uma opção de compra em comparação ao imóvel novo no município de São Paulo, revelando uma geografia da pressão imobiliária e a consequente dificuldade de moradia no município.

Como descobrimos nas entrevistas, ainda que a financiadora seja responsável por realizar o leilão, é a presença dos arrematadores do bem imóvel que intensifica a expulsão. A frase “Torça para que ninguém compre” aparece nas falas dos endividados, revelando em que plano a expulsão se concretiza: é no embate pela posse. Além disso, aproximar esses dois mapeamentos comprova a pressão pela moradia no município de São Paulo, em que o leilão se evidencia como "solução" nesse contexto. Consolidamos assim o interesse em ampliar os estudos sobre os leilões de imóveis.

\section{Novos contextos e desafios}

Nos dez anos que separam o início da pesquisa dos tempos atuais, assistimos ao crescimento do endividamento imobiliário. Em dados da Série Histórica da Pesquisa de Endividamento e Inadimplência do Consumidor (PEIC), monitorados desde 2004, com abrangência no município de São Paulo, constatamos esse crescimento entre os anos de 2010 e 2017, tanto nas famílias com renda menor quanto naquelas com renda maior, de dez salários mínimos (MARTINS, 2019). O Programa Minha Casa Minha Vida (PMCMV) tornou-se um caminho de endividamento para 
muitas famílias. Os subsídios para as faixas 2 e 3 o promoveram. Para a faixa 1, fica o endividamento constituído pelo condomínio, o que não será estudado aqui, mas deve ser mencionado. Seguimos assim enfrentando o primeiro desafio, a saber: tirá-lo da sombra no debate social crítico na produção do espaço urbano. Na sequência, avançamos em nossas pesquisas, considerando a metrópole do Rio de Janeiro.

É necessário dizer que alguns desafios de método também nos acompanhavam. A pesquisa iniciada em São Paulo foi realizada em proximidade com a Ritmanálise, de Henri Lefebvre (1992). Dentre outros elementos, o autor aborda nessa obra a manipulação do tempo, tratando da dominação do tempo social por meio "do ritmo próprio do capital de produzir e de destruir" (1992, p. 76; tradução nossa). Assim, o endividamento foi compreendido como um elemento coercitivo capaz de impor novos ritmos de exploração ao trabalhador em seu cotidiano metropolitano.

À medida que a pesquisa foi avançando para o Rio de Janeiro, a apreensão da obra foi "ganhando corpo" (MARTINS, 2020). Passamos a considerar a centralidade do corpo sensível como momento do conhecimento crítico. Nessa perspectiva, chegamos aos debates que compreendem clivagens e aproximações entre abordagens feministas, raciais e de classe. Segundo Revol (2019, p. 18), "estariam abertos os diálogos para uma compreensão e respeito mais profundos às alteridades, contra dominações de gênero, por exemplo”. O desafio ganhava mais uma camada.

Com a ampliação generalizada do endividamento, a pesquisa prosseguiu focada nos editais de leilões de imóveis da Caixa Econômica Federal (CEF), revelando aspectos geográficos do endividamento imobiliário urbano recente em municípios da Região Metropolitana do Rio de Janeiro. Para o Brasil, os estudos em questão são iniciais e têm como desafio o silenciamento do tema, conforme mencionado.

Diante de condições radicais de pobreza e da falta de moradia, o endividamento familiar parece consistir em questão menor, entretanto é um dado que vem crescendo em decorrência do estabelecimento de marcos jurídicos que conferiram maior agilidade às instituições financeiras na retomada dos bens imóveis e na ampliação do financiamento nas edições do PMCMV, chegando às famílias de baixa renda. A geografia de riscos e vulnerabilidade dos endividados é em parte representada por meio das "expulsões silenciadas" contidas nos leilões de imóveis. Os dados recolhidos são agregados por municípios e, com base neles, foram construídas relações com contextos municipais de elevação de preços dos imóveis e ampliação do número de lançamentos imobiliários, de diminuição de renda do trabalho e aumento de desemprego. Isso será ilustrado pelo município de Itaboraí (RJ), que reúne muitos casos de imóveis leiloados e foi impactado pela crise e interrupção de obras, como a do Complexo Petroquímico do Rio de Janeiro (Comperj). 
É importante circunscrever a pesquisa dos leilões a um contexto mais amplo. A geografia urbana está presente na ampla literatura que trata da mundialização financeira (CHESNAIS, 2005) e da financeirização na produção do espaço urbano na América Latina (SHIMBO; RUFINO, 2015). A financeirização tem impactos nas condições de moradia no mundo, redesenhando políticas habitacionais no Brasil (ROLNIK, 2015).

Evitando vulgarizar o termo financeirização, nosso intuito aqui é não confundi-lo com a simples ampliação das relações creditícias na dinâmica econômica, tratando-o mais especificamente com base na construção de instrumentos financeiros (RYAN-COLLINS; LLOYD; MACFARLANE, 2017) pelos quais o controle de investimentos e de decisões sobre a produção do espaço urbano vislumbra mais a reprodução financeira e futura de ativos do que a mudança qualitativa do urbano no sentido do direito à cidade. Nesse arcabouço mais amplo, este projeto reconhece ainda a centralidade da habitação no processo de financeirização mundial por meio de sua commodificação (MARCUSE; MADDEN, 2016, p. 31). Tanto a expectativa de ampliação de mercados consumidores ancorada na ampliação de crédito como a criação de derivativos e de securitização apoiados em hipotecas e nas características dos próprios endividados são fronteiras de ampliação financeira no mundo todo. Apesar dessa amplitude, aponta-se para a complexidade no tratamento do tema, tendo em vista as particularidades de financiamentos e programas habitacionais existentes em cada país (AALBERS, 2017).

Para o Brasil, nossas pesquisas vêm revelando o crédito como importante forma de acesso à moradia em muitas metrópoles do país - e a dívida como consequência. De acordo com a série histórica da PEIC, considerando dados até fevereiro de 2020, o financiamento da casa (levando em conta o tipo de dívida) salta de $3 \%$ para 9,3\%. Nas famílias com mais de dez salários mínimos, esse salto é maior (de 5\% para 18\%, em julho de 2019, caindo para 16,5\% em janeiro de 2020), ao passo que nas famílias cuja renda corresponde a menos que dez salários mínimos vai de $2 \%$ para $7,7 \%$.

Outros dados são relevantes para esse mesmo período: a dívida com o carro não sofre mudança significativa e continua a ser de aproximadamente 10\%, enquanto a existência de pessoas muito endividadas permanece em torno de $13 \%$ a $14 \%$. Quase metade dos endividados tem pagamentos em atraso há mais de noventa dias, indicativo de que o referido acesso ao crédito se transforma em dívida.

A apreensão do processo de expansão da produção imobiliária ocorrida em grande parte nos anos 2000 vem sendo abordada em muitos estudos de geografia urbana (VOLOCHKO, 2015) por conta da elucidação de eixos de valorização imobiliária em inúmeras metrópoles e da constatação do aumento do número de 
lançamentos imobiliários e da transformação morfológica de muitas áreas urbanas, que, em uma década, receberam inúmeros condomínios e conjuntos habitacionais.

Entretanto, essa geografia dos lançamentos imobiliários, provocada, em sua maior parte, pela abertura de capitais nas incorporadoras (MARTINS, 2011) e pelo aporte de recursos da segunda etapa do PMCMV, deve ser compreendida à luz do ponto crítico dos financiamentos, quando a falta de pagamento implica o leilão do imóvel.

Este artigo aponta o caminho da ampliação do crédito e da dívida no modo de vida urbano, mas centra esforços na investigação sobre o endividamento. A ampliação da dívida provoca um agenciamento, uma organização do tempo futuro no que se refere aos tomadores de empréstimos, ou, melhor, conta com o comprometimento do trabalho futuro dos trabalhadores para sua realização. A administração da inadimplência pode ainda se transformar na elevação dos preços do crédito desde o início da dívida, assim como na passagem desta a diferentes níveis do sistema financeiro, a securitização.

Em um regime de precarização cada vez mais acentuada do trabalho, o endividamento tende a se tornar estrutural no cotidiano do morador das metrópoles, e a produção do espaço urbano está imbricada nesse processo. Além disso, o crédito e a dívida são vistos aqui como relações sociais. Neste contexto, recorreremos aos leilões de imóveis para revelar a geografia do endividamento urbano.

\section{Corporificando a alienação da habitação na Região Metropolitana do Rio de Janeiro}

É necessário ressaltar que, quando falamos em revelar a geografia do endividamento, não restringimos a geografia à simples localização das unidades leiloadas em um mapa, ainda que essa etapa seja fundamental. Temos de compreender os contextos. Como resultado preliminar de nossas pesquisas, apontamos que o endividamento representado nos leilões de imóveis vem ocorrendo de maneira mais acentuada em municípios de Região Metropolitana do Rio de Janeiro que passaram por incremento na produção do setor imobiliário e por projetos regionais de intervenção econômica, produzindo um contexto inicial de euforia e uma crise de empregos e renda na medida em que os projetos fracassaram.

Essa geografia pode ser desvendada por meio da localização dos municípios em que há maior ocorrência de leilões, desencadeando, assim, as verificações de lançamentos imobiliários, dados de renda e empregos. Outra variável que vem sendo trabalhada diz respeito à contratação de unidades, por município, do PMCMV, faixas 2 e 3. Essa análise nos leva a compreender possíveis resultantes do aumento de financiamento de imóveis dentro das faixas de renda específicas. 
Os primeiros desafios vão sendo enfrentados, quais sejam, tirar das sombras as investigações acerca da dívida com a casa e, em seguida, refletir geograficamente sobre essa dinâmica da produção do espaço. Entretanto, é necessário corporificar essa conversa. Tais sujeitos não são abstratos; dados de classe, gênero e raça têm de ser entrecruzados. Para Bueno e Nunes (2019, p. 263), "o diferencial do trabalho feminino por classe, cor ou raça, orientação sexual, idade, ainda é um tema que precisa ser pesquisado a partir do olhar geográfico, considerando a importância do lugar como uma categoria de análise atravessada pelos marcadores sociais”.

Adicionalmente, a pesquisa dos leilões tem como pano de fundo uma reflexão sobre a dificuldade relativa à moradia na produção do espaço urbano, ressaltando o processo contemporâneo de alienação da habitação em dinâmicas metropolitanas. Para melhor circunscrever o que denominamos aqui alienação da moradia, é necessário elucidar que se trata de um esgarçamento da noção de alienação em Marx (1985), em que "alienação” significa estranhamento, coisificação, exteriorização.

"A ideia é raramente aplicada à moradia, mas deveria ser. [...] Se algo é 'alienável', é passível de troca, cambiável. Pode ser comprado e vendido. Alienação é, portanto, precondição para toda propriedade privada” (MARCUSE; MADDEN, 2016, p. 56; tradução nossa). Os termos dessa troca e as formas que essa propriedade vai assumindo se modificam, e parte do projeto busca atualizar tais questões, levando em conta especialmente a habitação como mercadoria financeirizada, ou seja, o imóvel financiado. A condição desse financiamento, que posterga a propriedade ao devedor em muitos anos, traz enorme insegurança ao morador (MARTINS, 2019).

É preciso refletir ainda sobre o fato de que, no contexto das cidades brasileiras, há um longo percurso para tratar das inúmeras formas assumidas pela habitação no processo de alienação. Mas esta pesquisa aponta para o salto qualitativo da relação de alienação nos conteúdos financeiros que vêm participando dos processos de urbanização da metrópole na última década.

Marcuse e Madden (2016, p. 6o; tradução nossa) afirmam que a "experiência da alienação da habitação, na sociedade contemporânea, significa, desta forma, insegurança e enfraquecimento. Isso é fomentado pela commodificação, pela expulsão e despossessão, além de exacerbado pela desigualdade. A alienação da moradia é um processo doloroso, por vezes traumático, uma experiência de divergência entre moradia e habitação".

Assim, para revelar parte da geografia das expulsões, esta pesquisa utiliza metodologias já exercitadas durante o doutorado, com enfoque em São Paulo. Por essa razão, alguns procedimentos já conhecidos facilitaram a sistematização de dados e a reflexão geográfica sobre eles. O primeiro elemento é a diferenciação entre 
os leilões judiciais e extrajudiciais, que dizem respeito à necessidade de o credor passar por uma instância jurídica para chegar ao leilão. O segundo ponto é o impacto da Lei de Alienação Fiduciária² (BRASIL, 1997) na agilização da retomada de bens imóveis pelas agências financiadoras. Os casos provenientes de alienação fiduciária vão a leilão de forma extrajudicial. É possível reconhecer a efetividade dessa lei nos editais consultados. $O$ terceiro é relativo à compreensão das etapas que são obrigatórias para que o imóvel vá a leilão. Dentre elas, está o aviso ao endividado. Muitos moradores, evitando o leilão, se tornam “desaparecidos” (MARTINS, 2011).

Inicialmente, foram estudados os leilões com base em sua publicação em mídia impressa, etapa obrigatória para as instituições financeiras. Nessa ocasião, dados sobre as características dos leilões constavam nos anúncios, tais como a presença da alienação fiduciária. Atualmente, a disponibilidade dos editais no site oficial da CEF oferece mais elementos e segurança na construção de uma amostra, mas a indisponibilidade eventual dos dados nos sites pode nos fazer recorrer novamente às leiloadoras. Vale ressaltar que na atualidade dispomos de sequências de editais completamente ancorados no instrumento da alienação fiduciária.

É necessário apontar ainda os possíveis motivos para um imóvel ir a leilão. Além dos Sistemas de Financiamento (Sistema Financeiro de Habitação, SFH, e Sistema Financeiro Imobiliário, SFI), os leilões de imóveis obedecem à solução de diversas formas de endividamento: o resultado da dívida gerada pela cobrança das taxas de condomínio ou de Imposto Predial e Territorial Urbano (IPTU) ou os imóveis leiloados porque entraram como garantia na compra de outras mercadorias e podem estar envolvidos em questões trabalhistas ou processos de outra natureza resolvidos por meio do resgate e da venda de bens, dentre eles o imobiliário. Esses dados são filtrados durante a coleta, para que possamos focar os imóveis leiloados com financiamentos recentes, sob alienação fiduciária.

A formação dos bancos de dados nesta pesquisa é rigorosa, ao não misturar leilões com motivos distintos e ao não contar mais de uma vez um imóvel que vai a leilão seguidamente, no cumprimento das etapas obrigatórias, ou que apareça em leiloadoras diferentes ao mesmo tempo. Tais cuidados permitem reunir dados e trabalhar com sua localização.

O levantamento de alguns dados é central em nossa pesquisa, tal como a situação de ocupação dos imóveis nos lotes leiloados. Anteriormente identificávamos grande proporção de imóveis ocupados, mas, no caso daqueles da CEF, esse dado atinge 100\%, reforçando o caráter do leilão como agilizador da expulsão imobiliária.

2. Lei $n^{\circ} 9.514$ de 1997, que passou a operar mais efetivamente a partir do ano de 2003. É responsável por separar posse e propriedade do bem imóvel, fazendo com que esses elementos só se reúnam ao final do endividamento. Agiliza a retomada do bem - portanto, a expulsão do morador. 
Outro dado gira em torno das áreas médias e dos preços médios dos imóveis. Tratase de um elemento que pode ser um indício de que os leilões, amplamente, fazem circular a única residência das famílias de menor renda, pois apresentam dimensões reduzidas (e estão ocupados). Por fim, interessam o mapeamento das unidades leiloadas e os dados de concentração de casos por município.

De modo correlato, houve a tentativa de identificar tanto obras do Programa de Aceleração do Crescimento (PAC) e do PMCMV nos municípios com maior número de casos de leilões como reestruturações viárias e investimentos ligados ao setor de óleo e gás em tais municípios e a dinâmica imobiliária (elevação de preços por metro quadrado e número de lançamentos).

Em levantamentos preliminares e que agora têm foco na CEF, agente financiador que concentra grande parte dos contratos, foi possível identificar a efetividade de elementos que se apresentavam ainda nascentes na época dos primeiros estudos. A Lei de Alienação Fiduciária (BRASIL, 1997) se disseminou nas formas de contratação de crédito, presentes em contratos que vão desde imóveis com subsídios do PMCMV, com exceção da primeira faixa, até os imóveis em distintas faixas de preço, acelerando os aspectos de retomada do bem.

O financiamento imobiliário se ampliou como acesso à habitação, questão que despontou apenas em meados da primeira década de 2000. Concretizou-se a aceleração na retomada e no número de imóveis retomados, com ampliação dos índices. De 2010 para 2016, o aumento foi de 93\%, sem dados de distribuição geográfica, segundo o Portal de Economia G1 (LAPORTA, 2016). Atualmente, taxas de juros são reduzidas, e em contextos de crise novos produtos são forjados entre bancos e empresas para utilizar a casa própria como lastro de tomada de empréstimos, como identificamos em notícia veiculada por imprensa especializada (ABECIP, 2019).

A totalidade dos imóveis leiloados foi comprada em regime de alienação fiduciária. Em anos anteriores, o aumento tanto das taxas para o financiamento como do desemprego provocou a realização de maior número de leilões e de distratos, além de estoques de lançamentos imobiliários parados.

Vale lembrar que há um mercado de compradores interessados em leilões, de forma que imóveis localizados em centralidades sofrem mais pressão para desocupação. Nesse contexto de ampliação do endividamento imobiliário, torna-se urgente compreender em detalhes o avanço desse processo, que acaba por se refletir na condição da urbanização brasileira na atualidade.

Nosso foco agora se volta para o estabelecimento de relações entre os dados de leilão e dados gerais municipais, considerando renda, gênero, idade, entre outras informações, em uma reflexão mais ampla sobre o contexto social desse endividamento. A checagem acerca da presença do endividamento junto aos contratos 
relacionados com os subsídios do PMCMV pode apresentar um elemento a mais na compreensão desse programa. Por fim, é relevante verificar a efetividade dos leilões como instrumento de retomada de bens imóveis e da consequente expulsão de moradores, em escala metropolitana, em um processo de expulsão silenciosa. Desse modo, agregam-se ao debate elementos sobre a alienação da moradia e a resultante crise do direito à cidade.

A fim de refletir geograficamente sobre o endividamento habitacional no Rio de Janeiro, foi feito um recorte de pesquisas dos editais de leilão da CEF oriundos de alienação fiduciária dos anos de 2018 e 2019. Mais tarde, tais dados foram sintetizados em uma tabela ${ }^{3}$, que possibilitou estudar e traçar um perfil do endividado no âmbito da habitação, dentro da Região Metropolitana do Rio de Janeiro.

A tabela resultante reúne dados importantes para entender quais imóveis estão indo a leilão por dívida, como endereço, descrição de metragem, valor de avaliação e de venda, estado de ocupação. Com essas informações, já é possível efetuar as primeiras análises, como a presença numerosa, somente em 2018, de imóveis em situação de leilão em cidades como Itaboraí (21 imóveis), Nova Iguaçu (19 imóveis), São Gonçalo (10 imóveis), Niterói (14 imóveis) e Maricá (87 imóveis), por exemplo, além da capital Rio de Janeiro (137 imóveis).

Nesse ínterim, é relevante salientar que, apesar de o número de habitações por município nem sempre se apresentar por meio de valores elevados, não deixa de ser um dado, no curto período de um ano, que aponta para a dificuldade com relação à moradia, remetendo a um impasse quanto ao direito à cidade. Cada dado apresentado representa um imóvel sendo retirado de uma família e posto em leilão após carência de noventa dias. Passados esses três meses de carência no pagamento das prestações, conforme a Lei da Alienação Fiduciária (BRASIL, 1997) vigente, o imóvel é direcionado para os editais de leilão e, somente há quatro anos, depois da Lei $n^{0}$ 13.465/2017, tornou-se obrigatória a notificação das datas, horários e locais de realização dos leilões.

Dos 330 imóveis estudados, 327 estão ocupados quando postos a leilão - em termos de porcentagem, correspondem a 99,09\% das habitações. Uma segunda análise, propiciada pela observação da tabela e pela tiragem da média do valor de avaliação dos imóveis por município, permitiu notar que o valor médio de avaliação das habitações presentes em Itaboraí ( $\mathrm{R} \$ 98.247,37)$ é o mais baixo dentre os supracitados, enquanto o de Niterói é o mais alto ( $\mathrm{R} \$ 533.437,22$ ).

3. A tabela, que não será reproduzida neste artigo dada sua amplitude, reúne dados dos editais da CEF, com identificação de localização, município da Região Metropolitana do Rio de Janeiro, dados de metragem quadrada e valores de negociação. 
Além destes, é relevante citar os valores médios de imóveis de outras cidades metropolitanas igualmente presentes nos editais. Em Nova Iguaçu, o valor médio é de $\mathrm{R} \$ 119.863,06$, um pouco mais alto que o de Magé, cuja média gira em torno de $\mathrm{R} \$ 116.966,67$.

Entre as cidades com médias mais baixas, estão Belford Roxo, com R $\$ 124 \cdot 347,20$, e São João de Meriti, com R\$144.857,14, por sua vez, abaixo de São Gonçalo, com valor médio de $\mathrm{R} \$ 183.672,50$. Outra cidade metropolitana que chamou nossa atenção foi Maricá, com o maior número de imóveis em leilões da CEF no ano de 2018, e cujo valor médio de avaliação é R\$263.301,50, mas ainda abaixo do de Niterói e da cidade do Rio de Janeiro, com média de R \$479.589,32. O valor de avaliação dos imóveis por município segue a dimensão de cada um, assim como a condição econômica e de acesso aos recursos das cidades. Quanto mais perto de grandes centros, como Rio de Janeiro e Niterói, mais bem avaliados são os imóveis financiados.

A análise da metragem média dos imóveis por município é outro dado obtido com base na tabela que nos ajuda a entender o cenário socioeconômico das cidades metropolitanas por trás dos grandes leilões e a caracterizar os imóveis que sofrem alienação da habitação e chegam a ser leiloados (onde se localizam, qual é seu perfil). Para facilitar o estudo dos dados, foi feito um recorte de casas e apartamentos apenas, sem a contabilização de terrenos e lojas presentes nos leilões (e na tabela). Dessa forma, o estudo se fecha em um olhar para a parcela da população que financia "o sonho da casa própria” e acaba por perdê-lo para o banco de maneira facilitada pela Lei de Alienação Fiduciária (BRASIL, 1997).

As metragens médias dos imóveis por município se mostram congruentes com os dados de valor de avaliação dos imóveis: as de Belford Roxo, com 54,21 m², e de Nova Iguaçu, com $57,94 \mathrm{~m}^{2}$, são as menores dentre aquelas das cidades metropolitanas. Itaboraí apresenta 73,29 m² de metragem média, e São Gonçalo, 79,06 m², imóveis também pequenos, não distantes da realidade socioeconômica e ocupacional dos municípios. São João de Meriti, por sua vez, tem média de $81,13 \mathrm{~m}^{2}$, semelhante à metragem média de Maricá, que é de $87,8 \mathrm{~m}^{2}$. Os imóveis do Rio de Janeiro, com média de $96,7 \mathrm{~m}^{2}$, só perdem para os de Niterói, os quais, com metragem média de 131,52 m², são os mais amplos, além de, como vimos, terem sido caracterizados como os de valor mais alto.

Com isso, e com base nas demais perspectivas, torna-se possível traçar certo perfil socioeconômico e refletir geograficamente, não somente no contexto espacial, como também no social, sobre os aspectos do endividamento imobiliário metropolitano no Rio de Janeiro. Uma perspectiva interessante é a análise da porcentagem de população ocupada, por município, obtida com dados do IBGE, com referência em 31 de dezembro de 2017. A parcela da população considerada ocupada é representada por "pessoas que, num determinado período de referência, 
trabalharam ou tinham trabalhado, ou não trabalharam por férias”, como elucidado pelo próprio IBGE.

Os dados são alarmantes e denunciam a realidade do morador da região metropolitana do estado. No Rio de Janeiro e em Niterói, a porcentagem de pessoas ocupadas é de 39,4\% e 39,3\%, respectivamente, e esses são os maiores índices nessa região. Cidades como Nova Iguaçu, com 13,6\%, Maricá, com 14,6\%, e Itaboraí, com $13,3 \%$, já denotam uma situação difícil dos moradores, porém a porcentagem de São Gonçalo, de 11,9\%, e a de Belford Roxo, de apenas 7,3\%, demonstram que quase 90\%, ou mais, da população de algumas cidades metropolitanas não contam com fonte de renda fixa. A posição de cada cidade endossa as demais análises feitas, formando um ranking socioeconômico pautado no estudo de trabalho e rendimento, como se vê na Figura 1.

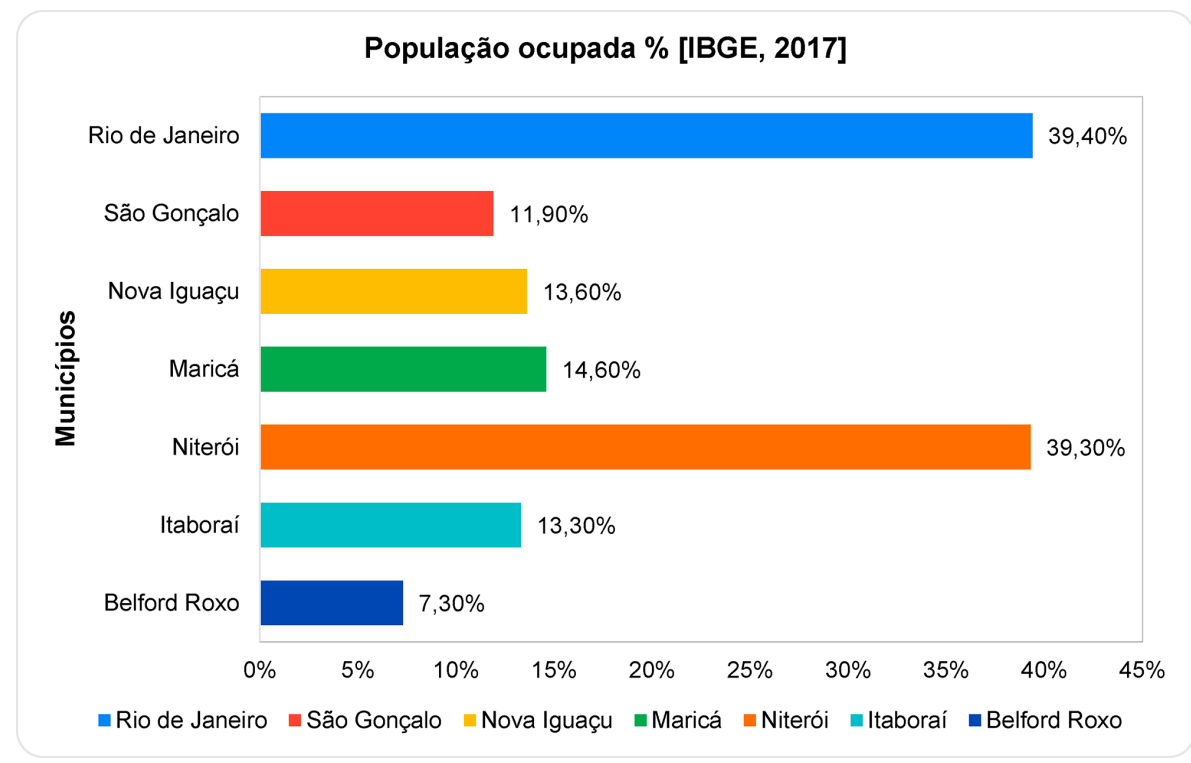

Figura 1. População ocupada

Fonte: IBGE, 2017. Elaborado por Ana Clara Guedes.

Outra perspectiva que pode enriquecer a caracterização socioeconômica e espacial da região metropolitana é a análise do percentual da população com rendimento nominal mensal per capita de até meio salário mínimo, dados levantados pelo IBGE no Censo Demográfico de 2010. Numa amostra de sete municípios metropolitanos, apenas um apresentou percentual abaixo de 30\%: Niterói, com $29,5 \%$, vem se mostrando uma realidade à parte na região metropolitana do estado. As demais cidades, como Maricá, com 33,8\%, São Gonçalo, com 34,5\%, e a capital Rio de Janeiro, com 31,4\%, apresentam índices maiores, ficando atrás apenas de 
Itaboraí, cuja porcentagem é de $37,7 \%$, de Nova Iguaçu, com 38,7\%, e de Belford Roxo, que tem o impressionante índice de $39,3 \%$ de sua população com rendimento mensal de até meio salário mínimo. A Figura 2 elucida essa problemática.

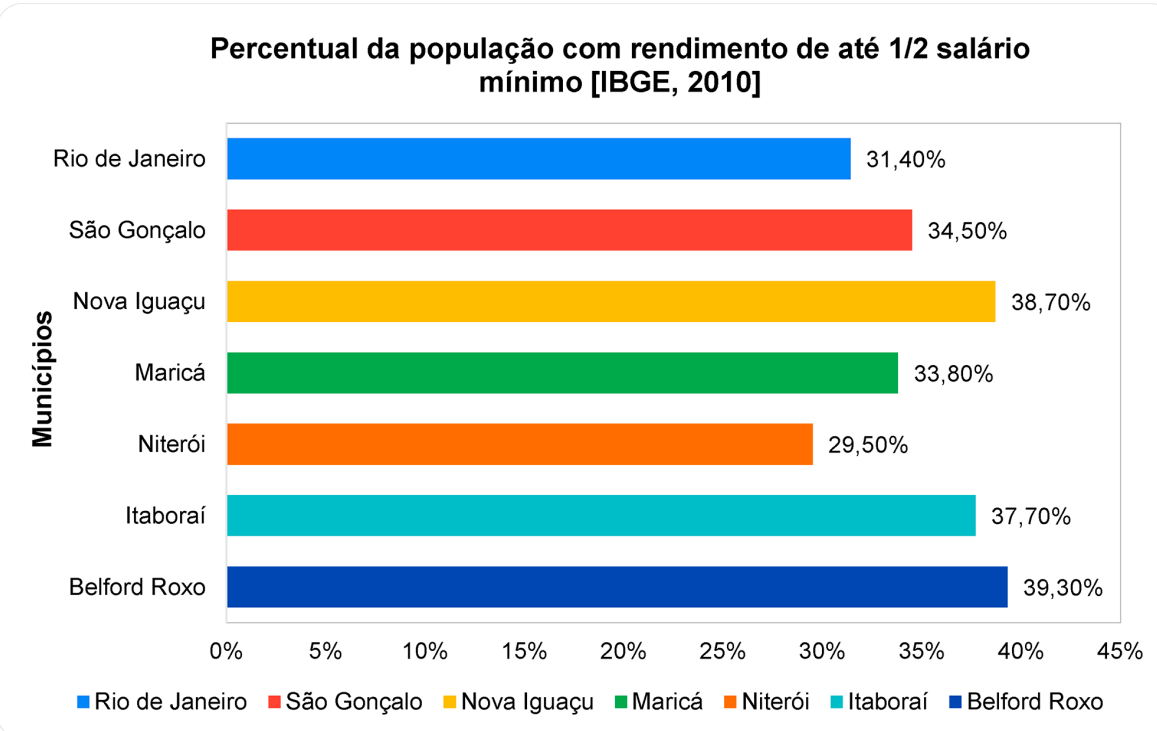

Figura 2. Percentual da população com rendimento de até meio salário mínimo Fonte: IBGE, Censo Demográfico 2010. Elaborado por Ana Clara Guedes.

É necessário também ressaltar a influência que grandes negócios, como o Comperj, exercem sobre algumas cidades metropolitanas. Algumas das que se destacaram negativamente nas análises socioeconômicas feitas durante a pesquisa, como Itaboraí e São Gonçalo, são exemplos de municípios do leste metropolitano que sofreram impactos urbanos decorrentes dessas obras.

No que diz respeito a Itaboraí, tem-se que, com o início das obras do Comperj, a dinâmica territorial do município foi drasticamente alterada. Primeiro, a chegada de empresas de diversos segmentos, boa parte delas, inclusive, prestadoras de serviços. Concomitantemente à movimentação de operários, houve necessidade de hospedagem e alimentação, além da expressiva expansão do setor imobiliário, não só comercial como residencial. São Gonçalo, por sua vez, apesar do crescimento pouco expressivo nesse período (2,23\%), na comparação com o de Itaboraí (16,68\%), apresentou duas tendências opostas, uma proveniente das alterações na dinâmica do mercado imobiliário, com o crescimento do ritmo dos lançamentos de novos empreendimentos imobiliários, e a outra evidenciada na expansão e no adensamento dos assentamentos populares precários (BINSZTOK; BARBOSA, 2018).

Há, ainda, o projeto do Arco Metropolitano, elaborado para facilitar o transporte de cargas e o escoamento da produção da região pelo porto de Itaguaí. 
O traçado do arco foi pensado inicialmente para chegar até o Comperj, porém foi estendido, depois, até o município de Maricá. O mapa a seguir, na Figura 3, identifica os municípios metropolitanos que sofreram afetações por conta do projeto e a congruência com a lista de cidades mais frequentes, no que diz respeito à presença na tabela já mencionada e nos dados supracitados.

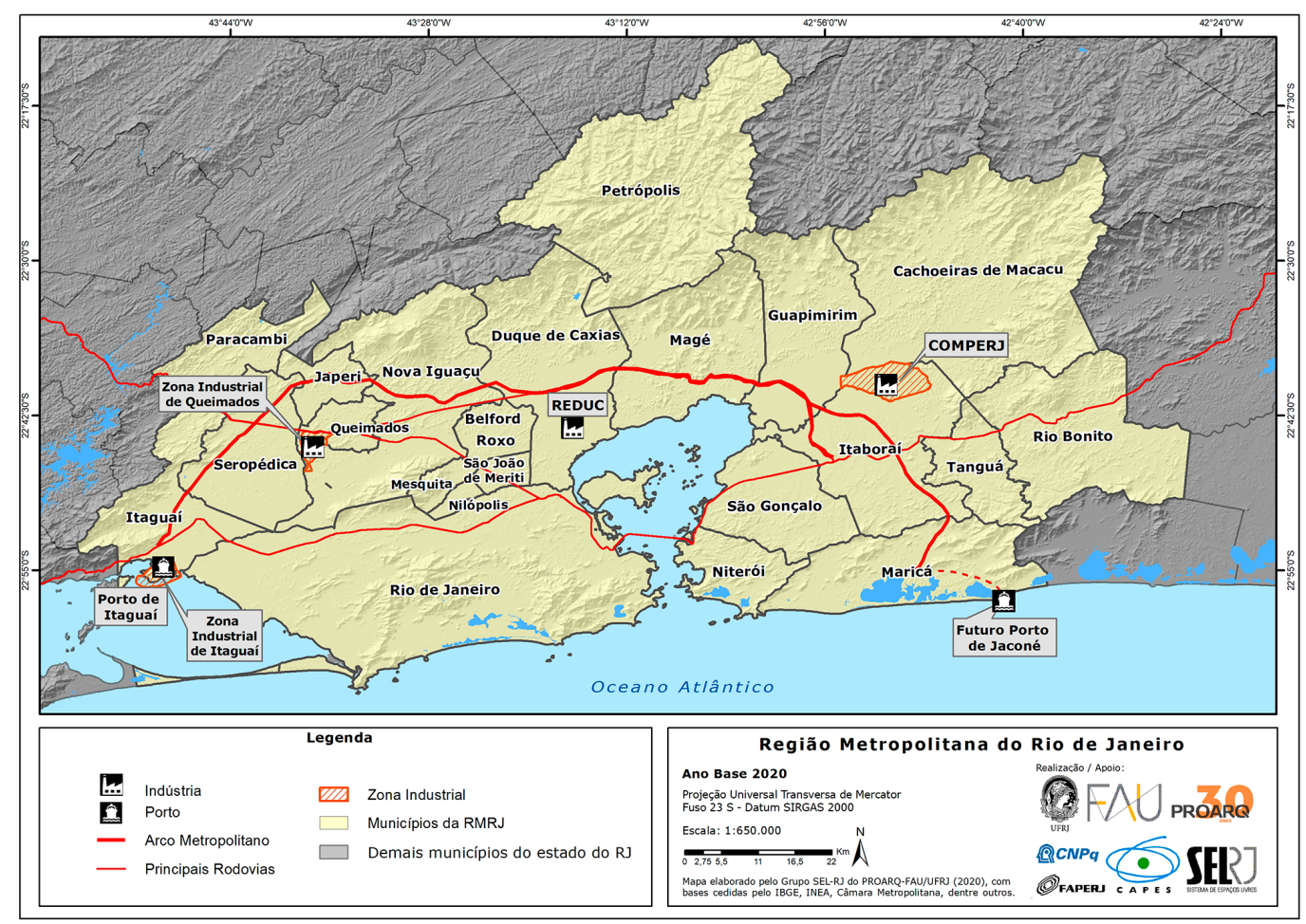

Figura 3. O Arco Metropolitano e a logística regional

Fonte: II Colóquio Contextos Metropolitanos no Rio de Janeiro. Org. Sistemas de Espaços Livres no Rio de Janeiro (SEL/RJ), 2020. Disponível em: https://www.even3.com.br/ccmrj2021/. Acesso em: 27 set. 2021.

\section{Apontamentos e questões para a generificação do endividamento imobiliário}

Constatou-se que municípios mais frequentes em nossos dados apresentavam, concomitantemente, informações que apontavam para a fragilidade econômica e social de parte expressiva da população. Dinâmicas territoriais oriundas de grandes obras, quando interrompidas no período de crise posterior a 2014, podem ter gerado expectativas frustradas de ganhos, endividamento e perda de imóveis.

Entretanto, dar corpo aos endividados não é tarefa fácil. Os dados de contratação dos empréstimos não estão organizados em base única ou nem sequer foram divulgados. Mesmo os dados de contratantes de crédito via PMCMV não estão disponíveis, e essa condição tem piorado desde 2018. Para avançarmos nesse olhar, passamos a considerar dados mais gerais, em recortes municipais, para construir um caminho de elucidação. 
As Figuras 4 e 5 relacionam os municípios mais incidentes nos leilões de imóveis à razão entre o rendimento médio das mulheres em face do rendimento dos homens. Há congruência dos menores valores dessa razão com os municípios que mais aparecem nos leilões, dando sinais de que os contextos sociais gerais podem nos levar a considerar maior exposição de mulheres ao endividamento imobiliário.

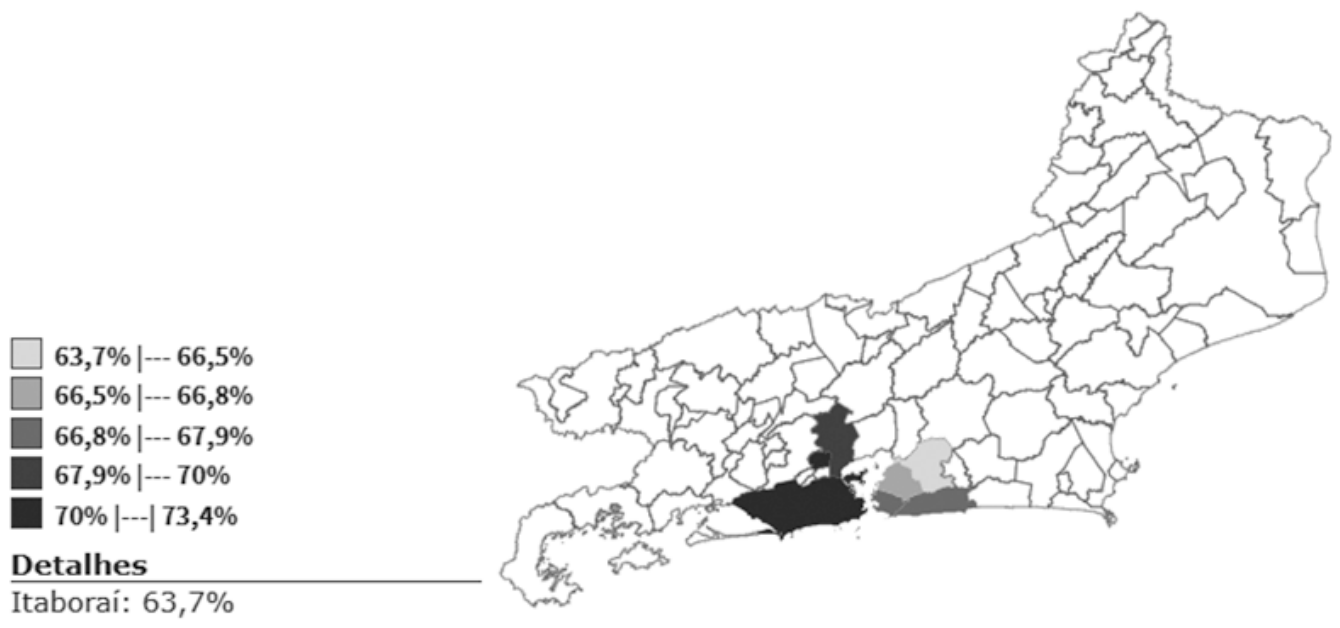

Figura 4. Razão entre o rendimento de mulheres e homens - municípios da Região Metropolitana do Rio de Janeiro

Fonte: IBGE, Censo Demográfico 2010.

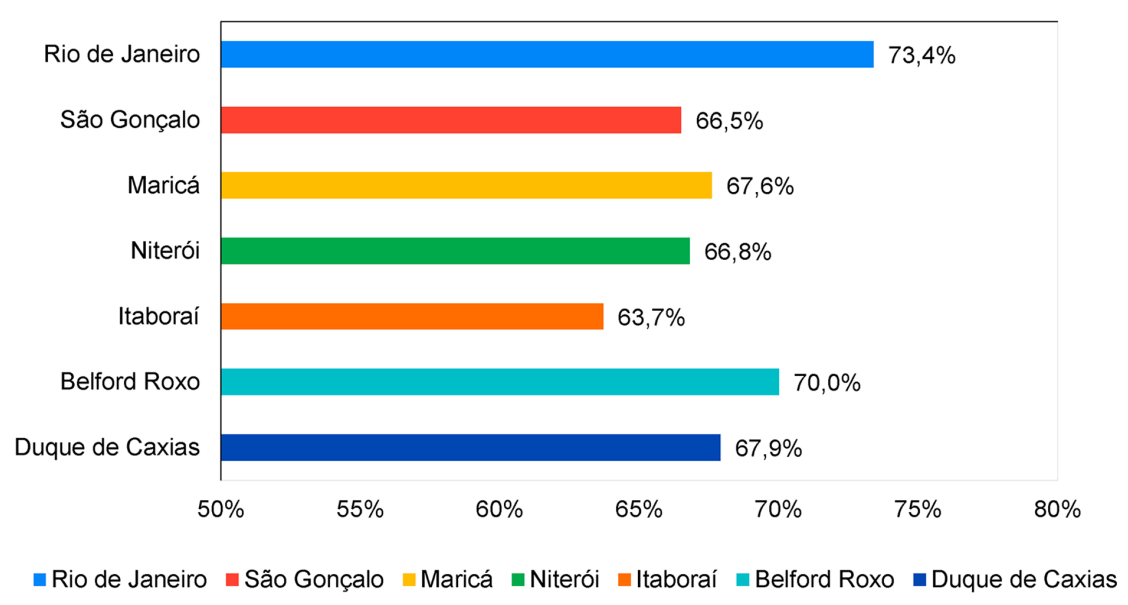

Figura 5. Razão de rendimentos entre mulheres e homens - municípios da Região Metropolitana do Rio de Janeiro

Fonte: IBGE, Censo Demográfico 2010. Elaborado por Ana Clara Guedes.

Enfrentando os desafios recentes da generificação do debate, obtivemos dados que se somam à nossa reflexão inicial baseada no endividamento imobiliário. Contamos com o importante estudo organizado por Graciela Rodriguez (2020), 
cuja pesquisa situada em três cidades brasileiras revelou a menção feita pelas entrevistadas ao endividamento com a CEF, motivado pelo PMCMV, entre outras inúmeras situações, tais como adoecimento, violência doméstica aumentada em contextos de endividamento e a vulnerabilização das mulheres mais velhas (RODRIGUEZ, 2020, p. 15).

Corroborando esse estudo, no que tange ao estado do Rio de Janeiro, o relatório Perfil do consumidor superendividado e a atuação da Defensoria Pública na renegociação da dívida, coordenado por Carolina Dzimidas Haber, da Defensoria do Estado do Rio de Janeiro, traz dados que vão de 2012 até 2017. Do total, quase 30\% dos endividados tinha mais de setenta anos, e 20\% entre 55 e 59 anos. Dos 95 casos estudados, $66 \%$ se enquadravam no gênero feminino. Nossa pesquisa em amostras de leilões de imóveis da CEF possibilitou a construção de um conhecimento territorialmente situado. Dessa forma, temos buscado romper, de maneira metodológica, os impedimentos impostos pela pandemia, que dificultam a realização de entrevistas.

As recentes publicações de Gago e Cavallero (2016; 2020; 2021) representam não só um conjunto de investigações teóricas, como importante construção de uma rede de olhares e pesquisa que fortalecem nossas investigações. Por meio dessas autoras, a presença do endividamento vem sendo anunciada e questionada na agenda feminista. Com palavras de ordem tais como "Vivas, livres e sem dívidas nos queremos!” (GAGO; CAVALLERO, 2020), as pautas reconhecem o esgarçamento que o endividamento representa para a espoliação da mulher na sociedade contemporânea. Um segundo ponto consiste em acentuar de que modo isso se reflete na esfera doméstica. De acordo com Loureiro (2020, p. 157):

Essa realidade reforça a importância de pensarmos a casa, o lar, o espaço doméstico como uma espacialidade relevante em nossas pesquisas, especialmente como objeto de estudo das Geografias Feministas, descaracterizando a visão dominante do lar (como "doce lar”) reproduzida pela geografia humanística - amparada na experiência do homem "universal", visto que o lar pode ser (e é) um lugar de opressão patriarcal para mulheres e crianças.

A noção de direito à cidade, que muitas vezes nos guia nas reivindicações, precisa ser tensionada, na medida em que, segundo Tavares (2017, p. 7),

[...] a própria ideia socialmente construída de espaço urbano, de forma geral, coloca as mulheres em um lugar marginal e dito feminino: o espaço doméstico (espaço privado); enquanto os homens estão num lugar central, considerado naturalmente masculino: o espaço público, sinônimo de espaço urbano. 
Nossas pesquisas apontam que o endividamento imobiliário pode chegar como dimensão crítica no modo de vida das mulheres em níveis e dimensões distintos. Considerando os dados gerais de renda, mulheres recebem menos que homens. Quanto à tipificação da inserção no mundo do trabalho, a hierarquização construída entre trabalho produtivo e reprodutivo provoca subalternização dos postos vinculados aos trabalhos de cuidado, de pessoas, doméstico e de saúde.

Esses postos de trabalho, em sua maioria, são ocupados por mulheres. Para Bueno e Nunes (2019, p. 261):

Fruto de uma inserção laboral marcada por um ideário essencialista baseado em relações de gênero patriarcais, que argumentam que 0 lugar social das mulheres é o espaço reprodutivo. E as ocupações no espaço produtivo resultam da qualificação inata das mulheres para o ambiente doméstico. Essas ocupações são desvalorizadas, econômica e socialmente. Hoje, as mulheres atuam em diversas profissões, mas ainda ocupam, majoritariamente, guetos de trabalho feminino, [...].

Esse primeiro ponto, quando acionado na dinâmica de endividamento, põe as mulheres em condições piores que as dos homens, especialmente no que se refere às possiblidades de pagamento das dívidas. Tal dificuldade será vencida mediante a assunção de novos postos de trabalho em uma mesma jornada ou na dívida não paga, com a consequente expulsão.

A expulsão pode vulnerabilizar essa mulher quando volta a contextos de moradia dos quais desejou sair, tanto por violência como por outros fatores. Quando a mulher não é a pessoa diretamente endividada, a dependência do pagamento das prestações pelo homem pode submetê-la a contextos indesejáveis.

Em trabalho preliminar de entrevistas, foi identificada a situação de desejo de romper o casamento, mas a consideração da dívida de longo prazo se revelou fator impeditivo para a consolidação da decisão. Certamente, o diálogo aproximado com mulheres endividadas por meio do financiamento imobiliário revelará pontos cegos, no entanto aguardamos melhores condições sanitárias relativas ao coronavírus para prosseguir nessa metodologia.

Uma última consideração é necessária: trazer relevo às pesquisas e corporificar sujeitos é um ato que vai além de ajustar uma pergunta. São dimensões profundas de exploração sentidas pelas pesquisadoras que vão buscando ar, chegar à superfície para respirar. Entretanto, os caminhos são áridos, em pavimentos endurecidos por camadas de práticas científicas pouco sensíveis. Esse limite se apresenta neste artigo. Com isso, apontamos para as necessárias parcerias. Precisamos do poder das teorias críticas modernas sobre o modo como significados e corpos são construídos, não para negar significados e corpos, e sim para viver em significados e corpos que tenham a possibilidade de um futuro (HARAWAY, 2009, p. 16). 


\section{Referências}

AALBERS, M. The variegated financialization of housing. International Journal of Urban and Regional Research, 41: in press, 2017.

ABECIP. Associação Brasileira das Entidades de Crédito Imobiliário e Poupança. Brasil Brokers tem novo modelo para venda de imóvel usado. Disponível em: https://www.abecip.org.br/imprensa/noticias/brasil-brokers-e-banco-inter-tem-novo-modelo-para-venda-de-imovel-usado. Acesso em: 20 dez. 2020.

BINSZTOK, J.; BARBOSA, J. L. Modernização fracassada. Dossiê Comperj. Rio de Janeiro: Consequência, 2018.

BRASIL. Lei de Alienação Fiduciária. Lei no 9.514, de 20 de novembro de 1997. Dispõe sobre o Sistema de Financiamento Imobiliário, institui a alienação fiduciária de coisa imóvel e dá outras providências. Diário Oficial da União, Brasília, DF: 21 nov. 1997 (ret. em 24 nov. 1997).

Lei $\mathrm{n}^{\circ} 13.465$ de 11 de julho de 2017. Disponível em: https://legislacao.presidencia. gov.br/atos/?tipo $=$ LEI\&numero $=13465 \& a n o=2017 \&$ ato $=534$ MTTU5EeZpWT6c4..$\quad$ Acesso em: 27 set. 2021.

BUENO, C. T.; NUNES, D. M. Geografias feministas: relações de gênero patriarcais: uma entrevista com Susana Maria Veleda da Silva. Revista Latino-Americana de Geografia e Gênero, v. 10, n. 1, p. 256-264, 2019.

CHESNAIS, F. A finança mundializada: raízes sociais e políticas, configuração, consequências. São Paulo: Boitempo, 2005.

GAGO, V., CAVAlLERO, L. Uma leitura feminista da dívida. Porto Alegre: Criação Humana, 2016.

Dívida, moradia e trabalho: uma agenda feminista para o pós-pandemia. Disponível em: https://editoraelefante.com.br/divida-moradia-e-trabalho-uma-agenda-feminista-para-o-pos-pandemia/. Acesso em: 20 dez. 20.

. La Batalla por la proprieadad em clave feminista. [s.d.]. Disponível em: http://revistaanfibia.com/ensayo/la-batalla-la-propiedad-clave-feminista/. Acesso em: $1^{\circ}$ jul. 2021.

HARAWAY, D. Saberes localizados: a questão da ciência para o feminismo e o privilégio da perspectiva parcial. Cadernos Pagu, Campinas, n. 5, p. 7-41, 2009. Disponível em: https:// periodicos.sbu.unicamp.br/ojs/index.php/cadpagu/article/view/1773. Acesso em: $20 \mathrm{dez}$. 2020.

IBGE. Instituto Brasileiro de Geografia e Estatística. Percentual da população com rendimento nominal mensal per capita de até 1/2 salário mínimo. Censo Demográfico 2010. Disponível em: https://www.ibge.gov.br/. Acesso em: 29 set. 2021.

. População ocupada: Cadastro Central de Empresas (Cempre) 2017. Disponível em: https://www.ibge.gov.br/estatisticas/economicas/comercio/9016-estatisticas-do-cadastro-central-de-empresas.html?=\&t=0-que-e. Acesso em: 29 set. 2021.

LAPORTA, T. Imóveis tomados pela Caixa por falta de pagamento sobem 53\% em 1 ano. 31 maio 2016. G1. Disponível em: http://g1.globo.com/economia/noticia/2016/05/imoveis-tomados-pela-caixa-por- falta-de-pagamento-sobem-53-em-1-ano.html. Acesso em: $20 \mathrm{dez}$. 2020. 
LEFEBVRE, H. Éléments de Rythmanalyse. Introduction à la conaissance des rythmes. Paris: Editions Syllepse, 1992. 116p.

HABER, C. D. (coord.). Perfil do consumidor superendividado e a atuação da Defensoria Pública na renegociação da dívida. Disponível em: https://defensoria.rj.def.br/uploads/arquivos/b7ca8cbd43c24d7f8aa11fce8483026e.pdf. Acesso em: 27 set. 2021.

LOUREIRO, A. L. A espacialidade aberta e relacional do lar: a arte de conciliar maternidade, trabalho doméstico e remoto na pandemia de Covid-19. Rev. Tamoios, São Gonçalo, ano 16, n. 1, esp. Covid-19, p. 154-166, maio 2020.

MARCUSE, P.; MADDEN, D. In defense of housing, the politics of crisis. London; New York: Verso, 2016.

MARTINS, F. E. S. A (re)produção social da escala metropolitana: um estudo sobre a abertura de capitais nas incorporadoras e sobre o endividamento imobiliário urbano em São Paulo. 2011. Tese (Doutorado) - Faculdade de Filosofia, Letras e Ciências Humanas, Universidade de São Paulo, São Paulo, 2011.

Níveis e dimensões da alienação da habitação: endividamento imobiliário e contextos de expulsão. In: SHIMBO, L.; RUFINO, B. (org.). Financeirização e estudos urbanos na América Latina. Rio de Janeiro: Letra Capital, 2019. p. 260-288.

Aproximações entre a Ritmanálise e a Geografia Urbana. Recursos teóricos e desafios metodológicos. In: LIMONAD, E.; BARBOSA, J. L. (org.). Geografias, reflexões, leituras, estudos. São Paulo: Max Limonad, 2020. p. 96-120.

MARX, K. El capital: Crítica de la economía política. Livro III, secção sétima. México: Fondo de Cultura Economica, 1985.

PEIC. Pesquisa de Endividamento e Inadimplência do Consumidor, 2021. Disponível em: http:// www.fecomercio.com.br/pesquisas/indice/peic. Acesso em: 27 set. 2021.

REVOL, C. Prefácio. In: LEFEBVRE, H. Éléments de rythmanalyse et autres essais sur les temporalités. Paris: Eterotopie, 2019.

RODRIGUEZ, G. Sobre o endividamento, as vozes das mulheres. In: (org.). $O$ sistema financeiro e o endividamento das mulheres. Rio de Janeiro: Instituto Equit - Gênero, Economia e Cidadania Global, 2020. Disponível em: https://www.equit.org.br/novo/?p=3172. Acesso em: 2 maio 2021.

ROLNIK, R. Guerra dos lugares: a colonização da terra e da moradia na era das finanças. São Paulo: Boitempo, 2015.

RYAN-COLLINS, J.; LLOYD, T.; MACFARLANE, L. Rethinking the economics of land and housing. London: ZED Books, 2017.

SHIMBO. L.; RUFINO, B. (org.). Financeirização e estudos urbanos na América Latina. Rio de Janeiro: Letra Capital, 2019.

TAVARES, R. B. Práticas sociais de resistência na perspectiva de gênero contra indiferença à diferença: por um planejamento de possibilidades. ENCONTRO NACIONAL DA ANPUR, 17., 2017, São Paulo. Anais [...]. São Paulo: Anpur, 2017. p. 1-12.

VOLOCHKO, D. A moradia como negócio e a valorização do espaço urbano metropolitano. A cidade como negócio. São Paulo: Contexto, 2015. 


\section{Flávia Elaine da Silva Martins}

Arquiteta e urbanista, geógrafa, mestre e doutora em Geografia pela Universidade de São Paulo (USP). Pesquisadora e professora do Programa de Pós-graduação em Geografia da Universidade Federal Fluminense (UFF). Professora associada do Departamento de Geografia da UFF.

Email: fesmartins@id.uff.br

ORCID: 0000-0001-8115-4201

Contribuição de autoria: conceituação; investigação/pesquisa; metodologia; supervisão/orientação; escrita - revisão e edição.

\section{Ana Clara Guedes}

Graduanda em Geografia pela Universidade Federal Fluminense (UFF). Pesquisadora bolsista de iniciação científica pelo Programa Institucional de Bolsas de Iniciação Científica (PIBIC/UFF).

Email: anaclaraguedesduarte@gmail.com

ORCID: 0000-0002-0863-277X

Contribuição de autoria: investigação/pesquisa; metodologia; investigação, pesquisa e metodologia, escrita - primeira redação.

Submissão: 20 de dezembro de 2020.

Aprovação: 26 de julho de 2021.

Como citar: MARTINS, F. E. S.; GUEDES, A. C. Generificando a pesquisa sobre endividamento imobiliário: primeiros desafios. Revista brasileira de estudos urbanos e regionais. Dossiê Território, Gênero e Interseccionalidades. v. 23, E202135, 2021. DOI 10.22296/2317-1529.rbeur.202135

Artigo licenciado sob Licença Creative Commons CC BY 4.0. https://creativecommons.org/licenses/by/4.o/deed.pt_BR 